\title{
DETERMINATION OF PESTICIDE MULTI-RESIDUES IN GREEN TEA USING A MODIFIED QUECHERS EXTRACTION AND LIQUID CHROMATOGRAPHY TANDEM MASS SPECTROMETRY TECHNIQUE
}

\author{
S.C. Tran ${ }^{a *}$, H.Th. LE ${ }^{a}$ and T.H. ThaI-NGUYEN ${ }^{b}$ \\ ${ }^{a}$ Department of Food Chemistry and Toxicology, National Institute for Food Control (NIFC), 13 Phan Huy Chu, \\ Hoan Kiem district, Hanoi. Vietnam \\ ${ }^{b}$ Department of Analytical Chemistry and Toxicology, Hanoi University of Pharmacy 13-15 Le Thanh Tong, \\ Hoan Kiem district, Hanoi. Vietnam
}

(Received: 15 December 2013; accepted: 3 April 2014)

\begin{abstract}
A modified QuEChERS method was developed and validated for determination of pesticide multi-residues in green tea by liquid chromatography tandem mass spectrometry. Lead acetate was first time used together with primary secondary amine and graphite carbon black to eliminate tannin, caffeine, and other pigments in tea and thus reduced the matrix effects. The method was compared to the original QuEChERS method as well as A.O.A.C. QuEChERS method. For accurate quantification, the matrix matched calibration technique was used. The method showed good performance in the concentration range from 0.01 to $1 \mathrm{mg} \mathrm{kg}^{-1}$. All pesticides could be quantified at and lower than $0.01 \mathrm{mg} \mathrm{kg}^{-1}$. Recoveries were from 70 to $120 \%$ and repeatabilities were $<15 \%$ RSD depending on the compounds. Keywords: pesticide multi-residues, green tea, QuEChERS, liquid chromatography-mass spectrometry
\end{abstract}

Tea is one of the most favoured beverages worldwide especially in Asian countries. The most tea producing and consuming countries are China, India, Sri Lanka, Kenya, Turkey, Indonesia, and Vietnam (Rediff.com, 2012). Pesticides were used in tea farming to control insects, mites, leaf-eating beetles, and caterpillars. Therefore, determination of pesticide residues in tea is an important contribution to a safer tea.

QuEChERS (Quick, easy, cheap, effective, rugged, and safe) is a sample preparation methodology for pesticide multi-residue analysis, which was first published by ANASTASSIADES and co-workers (2003). The method uses a single-step acetonitrile or buffered acetonitrile extraction and salting out liquid-liquid partitioning from the water in the sample with anhydrous magnesium sulphate. Then, the dispersive solid phase extraction (d-SPE) clean-up is done to remove excess water and matrix components with a combination of sorbents including $\mathrm{MgSO}_{4}$ and primary secondary amine (PSA). The final extracts are analysed by mass spectrometry (MS) technique after a liquid or gas chromatographic separation (A.O.A.C., 2010). This method has many advantages. Firstly, it is a multi-residue method, which can be applied to determine hundreds of pesticides in one single procedure. Secondly, the final extract in acetonitrile can be used both for gas chromatography and liquid chromatography. Last but not least, QuEChERS is definitely a cheap, easy, effective, rugged, and safe method like its name (LенотAY et al., 2005). For over a decade, QuEChERS has been developing quickly and was accepted by many international organizations (e.g. A.O.A.C. No.

\footnotetext{
* To whom correspondence should be addressed.

Phone: +84-4-3972 8880; fax: +84-4-3971 4512; e-mail: caoson32@gmail.com
} 
2007.01, BS EN 15662:2008, etc.) for determination of pesticide residues in fruit and vegetables (BS EN, 2008; A.O.A.C., 2010). The A.O.A.C. method uses acetate buffer as solvent extraction, while EN method uses citrate buffer. The $\mathrm{pH}$ value around 4.5 to 5.5 of buffers is favourable with the acidic or basic compounds and matrices. Pesticide multi-class, multi-residue determination relies on the QuEChERS extraction combined to LC-MS/MS and/or GC-MS(/MS) instrumentation could be used to identify a few hundreds of pesticides in one single test (LeHotay et al., 2005; NGUYEN et al., 2010; DAI et al., 2011). Its applications have also spread to other matrices like tea, herb, rice, and other grains (STEINIGER et al., 2010; Chen et al., 2011; FAn et al. 2013; GuAN et al., 2013; RAJski et al., 2013).

Determination of pesticides in tea is somewhat difficult, due to the presence of large amounts of polyphenols, caffeine, and especially tannin (GrAHAM, 1992), which can result in a high matrix effect. A larger number of analytical methods have been published for the determination of pesticide residues in tea. Some methods include the solvent extraction combined to many clean-up techniques, such as solid phase extraction (SPE) or gel permeation chromatography (GPC) (HuANG et al., 2007; CHо et al., 2008). These methods, however, are time- and labour-consuming and require large volumes of various kinds of solvents. Recently, QuEChERS method has been applied to extract pesticides from tea (STEINIGER et al., 2010; Chen et al., 2011; Lozano et al., 2012; Guan et al., 2013; Rajski et al., 2013; Shoeibi et al., 2013). To deal with the matrix effect problem, many techniques have been tried including a sample dilution, matrix calibration, various types and amounts of sorbent addition, or SPE cleanup (STAHNKE et al., 2012; FAn et al., 2013; GuAN et al., 2013; RAJSKI et al., 2013; WANG et al., 2013). However, the high amount of tannin in tea requires a method with a further clean-up step. Until now, the reaction of tannin with lead(II) acetate forming lead(II) tannate is used for the isolation of tannin from green tea.

The aim of this work is the evaluation of lead(II) acetate as a clean-up material for pesticides analysis in tea matrices. This study also included the validation results of a LCMS/MS technique combined with a modified QuEChERS procedure using lead(II) acetate in the partitioning step for determination of pesticide multi-residues in green tea.

\section{Materials and methods}

\subsection{Chemicals and reagents}

All pesticide reference standards, of purity $\geq 95 \%$, were from Dr. Ehrenstorfer (Augsburg, Germany). These pesticides (showed in Table 1) were chosen based on their use in tea crops and were applicable with LC-MS/MS. The application could be generally spread to other pesticides. The internal standard, triphenyl phosphate (TPP), was from Sigma-Aldrich (St. Louis, MO, USA). The stock solutions of $1000 \mu \mathrm{g} \mathrm{ml}^{-1}$ were prepared in acetonitrile and stored in dark at $-4{ }^{\circ} \mathrm{C}$. The intermediate standard-mix solutions of $0.1,1,5$, and $10 \mu \mathrm{g} \mathrm{ml}{ }^{-1}$ were diluted from stock solutions in acetonitrile. TPP working solution was of $2 \mu \mathrm{g} \mathrm{ml}^{-1}$.

Acetonitrile and methanol of HPLC grade were from Merck (Darmstadt, Germany). Acetic acid, anhydrous magnesium sulphate, sodium acetate trihydrate, lead acetate, and sodium chloride were also supplied by Merck. Primary-secondary amine (PSA) and graphite carbon black (GCB) sorbents were obtained from Agilent Technology (USA). Ultra-pure water was obtained by using a SG purification system (Germany). 
Table 1. List of pesticides with HPLC retention times and MS/MS conditions

\begin{tabular}{|c|c|c|c|c|}
\hline Pesticides & $\begin{array}{l}\text { Retention time } \\
\qquad(\mathrm{min})\end{array}$ & Precursor ion $(\mathrm{M}+\mathrm{H})$ & $\begin{array}{l}\text { Quantification ion } \\
\qquad(\mathrm{CE}, \mathrm{eV})\end{array}$ & $\begin{array}{c}\text { Confirmation ion } \\
(\mathrm{CE}, \mathrm{eV})\end{array}$ \\
\hline Acetochlor & 10.80 & 270.0 & 224 (13) & $148(25)$ \\
\hline Aldicarb & 8.03 & 213.0 & $116(15)$ & $89(15)$ \\
\hline Atrazine & 9.61 & 216.0 & $96(31)$ & 104 (37) \\
\hline Azoxystrobin & 9.83 & 404.0 & $372(19)$ & $344(31)$ \\
\hline Abamectin & 13.90 & 890.5 & $305(31)$ & $567.5(17)$ \\
\hline Acetamiprid & 6.90 & 223.0 & $126(25)$ & $56(19)$ \\
\hline Carbaryl & 9.10 & 202.0 & $145(13)$ & $127(37)$ \\
\hline Carbofuran & 8.74 & 222.0 & $165(15)$ & $123(29)$ \\
\hline Carbendazim & 5.35 & 192.0 & $160(23)$ & $132(39)$ \\
\hline Carboxin & 9.08 & 236.0 & $143(19)$ & $87(29)$ \\
\hline Dichlorvos & 8.71 & 221.0 & $109(23)$ & $127(18)$ \\
\hline Dimethoat & 7.03 & 230.0 & $199(13)$ & $125(27)$ \\
\hline Edifenphos & 11.00 & 311.0 & $283(17)$ & $109(35)$ \\
\hline Emamectin & 11.00 & 886.5 & $158(39)$ & $302(35)$ \\
\hline Fenobucarb & 10.10 & 208.0 & $152(11)$ & $95(19)$ \\
\hline Imidacloprid & 6.32 & 256.0 & $209(21)$ & $175(27)$ \\
\hline Indoxacarb & 11.30 & 528.0 & $249(21)$ & $293(17)$ \\
\hline Isoprocarb & 9.55 & 194.0 & $95(19)$ & $137(11)$ \\
\hline Methiocarb & 10.30 & 226.0 & $169(11)$ & $121(23)$ \\
\hline Methomyl & 4.89 & 163.0 & $88(13)$ & $106(13)$ \\
\hline Profenophos & 11.90 & 373.0 & $303(23)$ & $345(17)$ \\
\hline Propoxure & 8.67 & 210.0 & $111(19)$ & $93(31)$ \\
\hline Terbuconazole & 11.10 & 308.0 & $125(39)$ & $151(31)$ \\
\hline Thiamethoxam & 5.29 & 292.0 & $211(15)$ & $181(29)$ \\
\hline Trichlorfon & 6.97 & 257.0 & $109(23)$ & $221(15)$ \\
\hline TPP (IS) & 11.10 & 327.0 & $77(61)$ & - \\
\hline
\end{tabular}

Samples were dried Vietnamese green teas (produced from Camellia sinensis leaves and flower buds) collected from the market. Blank samples were chosen from the samples in which pesticides had not been detected.

\subsection{Instrumentation}

An AB Sciex 5500 triple quadrupole mass spectrometer (AB Sciex, USA) coupled with LC20AD high pressure pumps, column compartment, and autosampler (Shimadzu, Japan) was used to detect and quantify the pesticide residues. LC separation was obtained by using a X-Bridge BEH C18 $(150 \mathrm{~mm} \times 2.1 \mathrm{~mm}, 2.5 \mu \mathrm{m}$ particle size $)$ and a pre-column BEH C18 (5 $\mathrm{mm} \times 2.1 \mathrm{~mm}, 1.7 \mu \mathrm{m})$ (Waters, USA) with a mobile phase composed of $0.1 \%(\mathrm{v} / \mathrm{v})$ acetic acid in water (eluent A) and methanol (eluent B). The gradient program was initially set at $25 \% \mathrm{~B}$ in $1 \mathrm{~min}$ then increased linearly to $90 \% \mathrm{~B}$ over $8 \mathrm{~min}$. After that, the eluent composition was maintained at $90 \% \mathrm{~B}$ for $4 \mathrm{~min}$, and re-equilibrated over $3 \mathrm{~min}$. The flow rate used was kept constant at $0.7 \mathrm{ml} \mathrm{min}{ }^{-1}$. Total run time was $15 \mathrm{~min}$. The injection volume was $20 \mu \mathrm{l}$. 
The mass spectrometer was operated in positive ESI mode with capillary voltage and temperature set at $5000 \mathrm{~V}$ and $450{ }^{\circ} \mathrm{C}$, respectively. A Peak Scientific AB-3G gas generator (UK) was used to generate $\mathrm{N}_{2}$ used as curtain gas and air was used as source gas. Curtain gas, collision gas, source gas 1, and source gas 2 were set at 25 psi, 7 psi, 30 psi, and 20 psi, respectively. MS experiments were carried out in multiple reaction monitoring modes with two transitions for each pesticide (Table 1). The higher intensities of the precursor-to-product ion transition were used for quantification; the others were used for confirmation. In addition, the ion ratios were also the criteria for pesticide confirmation.

\subsection{Sample preparation}

A modified QuEChERS method was applied to extract pesticides in green tea samples. After homogenization, a $3 \mathrm{~g}$ portion of sample was weighed in a $50 \mathrm{ml}$ centrifuge tube. Internal standard (TPP) was added to make a sample concentration of $100 \mu \mathrm{g} \mathrm{kg}$. Then, $15 \mathrm{ml}$ of water was added for sample hydration. The tube was carefully shaken by hand for $30 \mathrm{~s}$ and let stand for $30 \mathrm{~min}$. After that, $15 \mathrm{ml}$ of acetonitrile were added and the tube samples were shaken vigorously by hand for $1 \mathrm{~min}$. A portion of $6.0 \mathrm{~g}$ of anhydrous $\mathrm{MgSO}_{4}, 1.5 \mathrm{~g}$ of $\mathrm{NaCl}$ and $1.5 \mathrm{~g}$ of $\mathrm{Pb}\left(\mathrm{CH}_{3} \mathrm{COO}\right)_{2}$ was gradually added and the tubes of samples were tightly capped, shaken as mentioned above, and centrifuged at 6000 r.p.m. $(3904 \times g)$ for 5 min. For clean-up, $1 \mathrm{ml}$ of supernatant was transferred to a $2 \mathrm{ml}$ centrifuge tube containing $150 \mathrm{mg}$ of anhydrous $\mathrm{MgSO}_{4}, 50 \mathrm{mg}$ of PSA, and $7.5 \mathrm{mg}$ of GCB. The tube was vortexed for $30 \mathrm{~s}$ and centrifuged at 12000 r.p.m. $(13684 \times \mathrm{g})$ for $1 \mathrm{~min}$. A portion of $0.5 \mathrm{ml}$ of the supernatant was dried under a nitrogen stream at $40{ }^{\circ} \mathrm{C}$. The residue was then reconstituted with $0.5 \mathrm{ml}$ of mobile phase $(0.1 \%$ acetic acid and acetonitrile, $75: 25)$ and the extract was filtered through a $0.2 \mu \mathrm{m}$ membrane (Minisart RC 15, Sartorius, Germany) to a LC-MS/MS sample vial. In this procedure, the sample weight was $3 \mathrm{~g}$ and the extract volume was $15 \mathrm{ml}$, so the sample was 5 times diluted.

\subsection{Matrix-matched calibration technique}

The blank tea sample was extracted with acetonitrile as mentioned above. In the clean-up step, $6 \mathrm{ml}$ of the acetonitrile extract was transferred to a $15 \mathrm{ml}$ centrifuge tube containing 900 $\mathrm{mg}$ of anhydrous $\mathrm{MgSO}_{4}, 300 \mathrm{mg}$ of PSA, and $45 \mathrm{mg}$ of GCB. The final extracts were used to prepare matrix-matched calibration solutions by diluting the intermediate standard-mix solutions to give the final concentrations of $0,1,2,20,100$, and $200 \mathrm{ng} \mathrm{ml}^{-1}$ (corresponding to $0,5,10,100,500$, and $1000 \mu \mathrm{g} \mathrm{kg}^{-1}$ in samples). These solutions were used to evaluate the recoveries and to quantify analytes in real samples. Furthermore, a series of standard solutions in solvent (acetonitrile) at the same concentration levels were also prepared for the assessment of matrix effects.

\subsection{Method validation}

The method was validated for linearity, matrix effects, limits of detection, repeatability, and recovery. To test the linearity, the matrix-matched calibration solutions were analysed. The matrix effects were assessed by comparing the slopes of matrix-matched calibration curves to solvent calibration curves and given in percentage. The repeatability and recovery was evaluated at three concentration levels (sample concentrations were 10, 100, and 1000 $\mu \mathrm{g} \mathrm{kg}^{-1}$ ) of spiked samples with 6 replicates per level. 


\section{Results and discussions}

\subsection{Optimization of LC-MS/MS}

The precursor ions, product ions, and collision energy were chosen and optimized by the injection of a pesticide solution of $100 \mathrm{ng} \mathrm{ml}^{-1}$ directly into mass spectrometry. The precursor ions were of the highest $\mathrm{m} / \mathrm{z}$ and most intense ion beam, which were $\mathrm{M}+\mathrm{H} \mathrm{m} / \mathrm{z}$ in most cases. Then, the product ions and collision energies were automatically optimized using the system software (Analyst). Other LC and MS parameters were also investigated to obtain peaks of Gaussian shape and the signal to noise ratios $(\mathrm{S} / \mathrm{N})$ of the $10 \mu \mathrm{g} \mathrm{kg}^{-1}$ matrix standard with values above 10. A chromatogram of a mixture of matrix pesticide standards is shown in Figure 1.

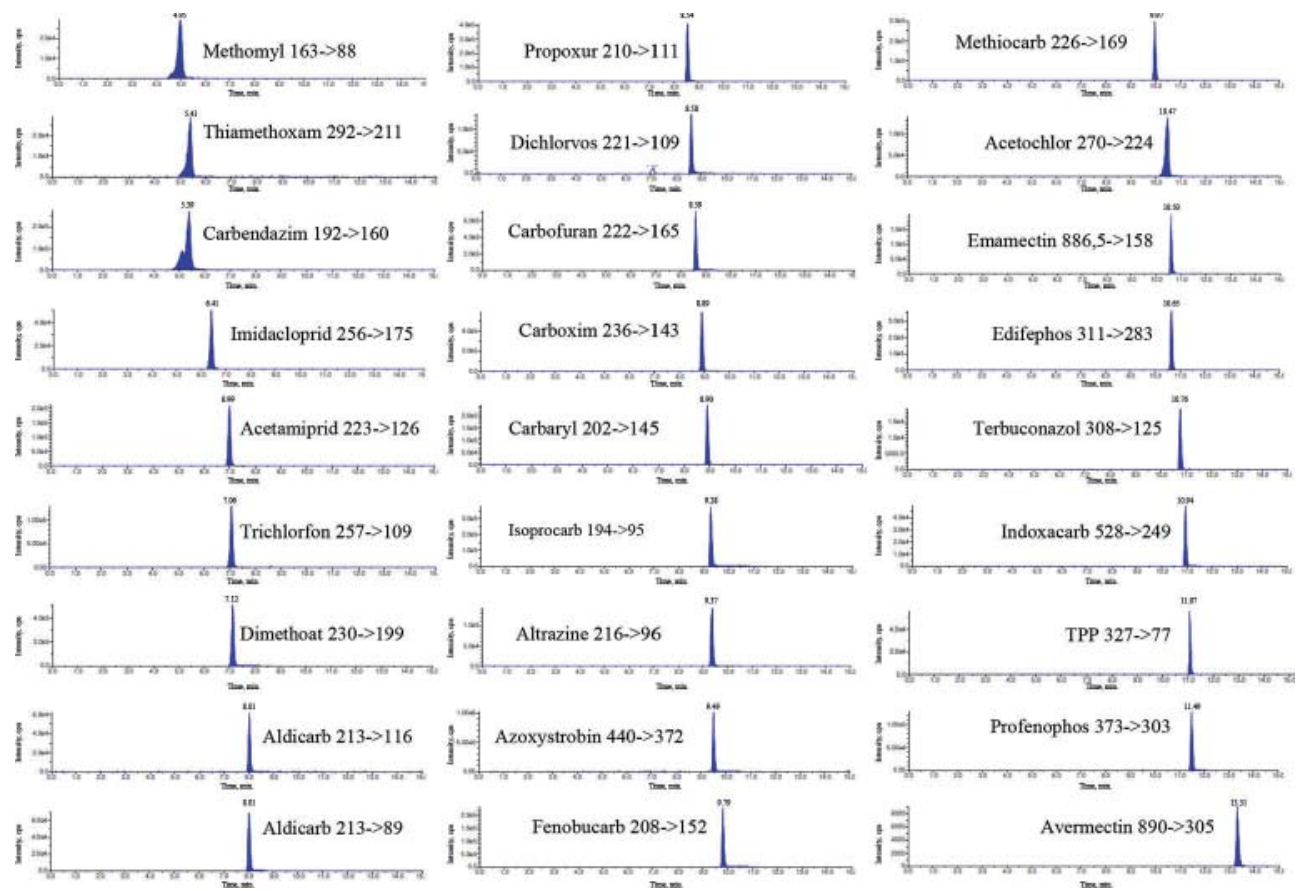

Fig. 1. Exact ions chromatogram of a matrix standard of 25 pesticides and internal standard TPP at the concentration of $100 \mathrm{\mu} \mathrm{kg} \mathrm{k}^{-1}$ (Annotations are the names and the transitions of the quantification ions, aldicarb showed two transitions)

Most of the peaks are symmetric except for methomyl, thiamethoxam and carbendazim peaks. These compounds are more polar than others and thus, have strong interaction with residual silanol groups on the packing surface of the LC column. Modifying the mobile phase with a buffer, amine, or ion-pairing reagent is used to improve the peak shape. However, the MS/MS detection could give enough selectivity and sensitivity to gain acceptable accuracy for these three compounds. 


\subsection{Investigation of sample preparation}

The QuEChERS extraction method showed good performances for many types of vegetables and fruit. The method requires a sample moisture content of about $80 \%$ or above for maximal pesticide extraction (ANASTASSIADES et al., 2003). Therefore, water was added to dried tea before extraction to hydrate the sample. To get the moisture content of around $80 \%$, the water to sample ratio was set at $5: 1(\mathrm{w} / \mathrm{w})$. The sample then was left for 30 min to ensure a complete hydration without further investigation of the amount of water and the soaking duration (Steiniger et al., 2010; Chen et al., 2011; RAJSKi et al., 2013).

Two versions of public QuEChERS method including the original version (ANASTASSIADES et al., 2003) and the A.O.A.C. version (LенотAY et al., 2005) were tested and compared to a modified QuEChERS method. The modified one relies on the addition of lead acetate $(1.5 \mathrm{~g})$ in the extraction step to adsorb polyphenols, caffeine, and pigments in tea and the addition of GCB in the clean-up step to remove chlorophylls. The extraction efficiencies, the co-extracted materials, and the extract $\mathrm{pH}$ values of the three methods were compared. $\mathrm{pH}$ values of the extracts obtained from original, A.O.A.C., and modified methods were 5.23, 5.76, and 5.63, respectively. The amount of co-extractives from the initial extraction solvent of the modified method was a half of those of the other methods (Table 2). Therefore, the matrix effects of this method were reduced. Figure 2 shows that the recoveries of eight compounds obtained with the proposed method were higher than the other ones. Most of these compounds are carbamate and organo-phosphorus insecticides. There were no significant differences in recoveries among the three methods for other analytes. After these experiments, we found that the use of lead acetate helped achieve a better cleaning and a higher recovery, overall. Besides, the green tea matrices, having a $\mathrm{pH}$ about 6 , did not require the addition of a $\mathrm{pH}$ buffer.

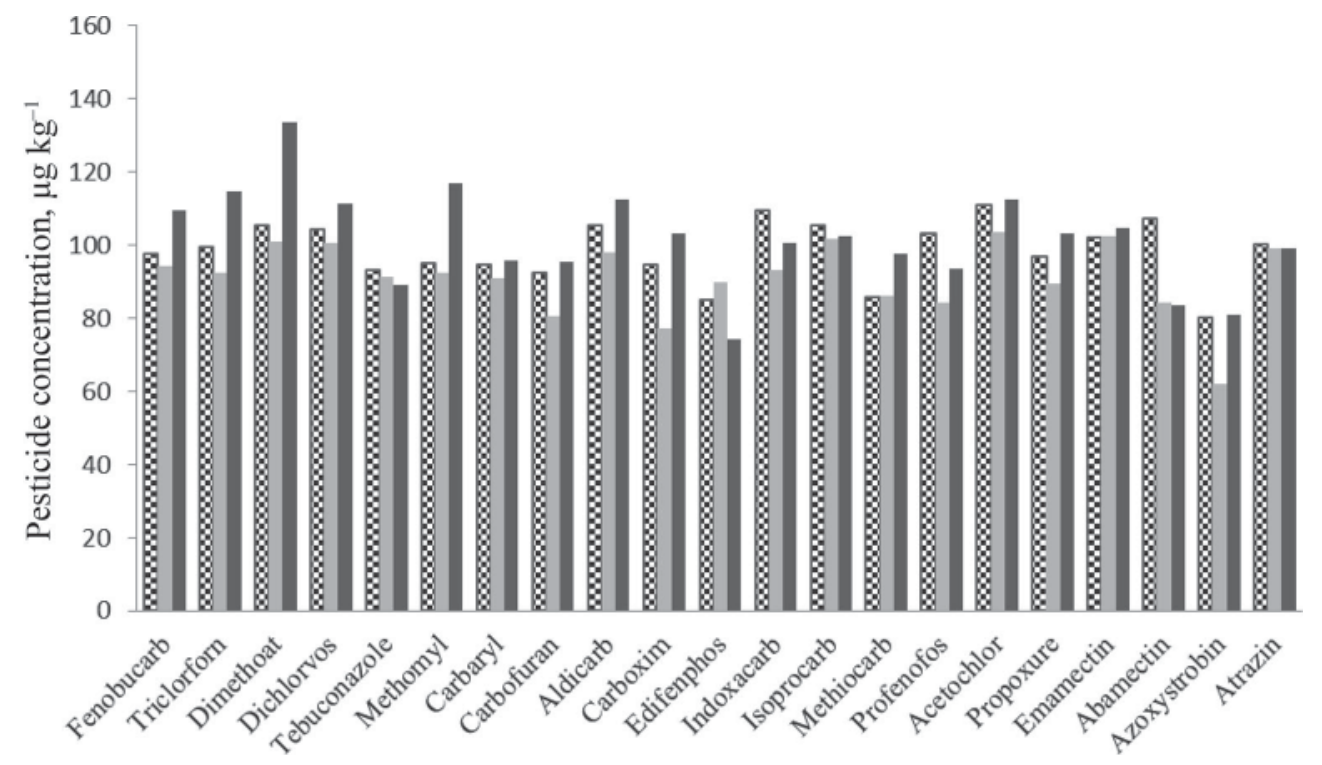

Fig. 2. Comparison of three QuEChERS methods ( 8 : the original method; : the AOAC method; : the modified method) for the extraction of pesticide residues in green tea 
Table 2. Co-extracted materials and $\mathrm{pH}$ values in $\mathrm{MeCN}$ or $0.1 \%$ acetic acid in $\mathrm{MeCN}$ extracts prior to d-SPE step

\begin{tabular}{|c|c|c|c|c|}
\hline QuEChERS method & Extraction solvent & Partitioning salts & $\mathrm{pH}$ & $\begin{array}{c}\text { Co-extracted } \\
\text { material }\left(\mathrm{mg} \mathrm{ml}^{-1}\right)\end{array}$ \\
\hline Original & $\mathrm{MeCN}$ & $\begin{array}{l}6 \mathrm{~g} \mathrm{MgSO}_{4} \\
\& 1.5 \mathrm{~g} \mathrm{NaCl}^{2}\end{array}$ & 5.23 & 20.5 \\
\hline AOAC & $\begin{array}{l}\mathrm{MeCN} \\
(0.1 \% \text { acetic acid })\end{array}$ & $\begin{array}{c}6 \mathrm{~g} \mathrm{MgSO}_{4} \& \\
1.5 \mathrm{~g} \mathrm{CH}_{3} \mathrm{COONa}\end{array}$ & 5.72 & 21.3 \\
\hline Modified & $\mathrm{MeCN}$ & $\begin{array}{c}6 \mathrm{~g} \mathrm{MgSO}_{4}, 1.5 \mathrm{~g} \\
\mathrm{NaCl}_{1} 1.5 \mathrm{~g} \\
\left(\mathrm{CH}_{3} \mathrm{COO}\right)_{2} \mathrm{~Pb}\end{array}$ & 5.63 & 10.5 \\
\hline
\end{tabular}

The optimal amount of lead acetate was also investigated. Different amounts of lead acetate including $0.5,1.0,1.5$, and $2.0 \mathrm{~g}$ were used in the extraction step and the recoveries of pesticides derived were compared. The more salt was used the better recovery was obtained. However, the recovery of the samples with above $1.5 \mathrm{~g}$ lead acetate decreased, because the pesticide absorption increased and the solubility of lead salt reached a limit. The highest recoveries for most pesticides were obtained when using $1.5 \mathrm{~g}$ of lead acetate.

In the dispersive SPE step, GCB was used to eliminate chlorophylls and some of the polyphenols and other pigments. The amount of GCB used was of $7.5 \mathrm{mg} \mathrm{ml}^{-1}$ of extract according to previous researches. GCB can absorb some planar pesticides when used at higher concentrations. In this investigation, the use of GCB gave equal or better recoveries for most pesticides (Fig. 3). The higher recoveries were obtained by the reduction of the matrix effect, which was a result of the application of GCB.

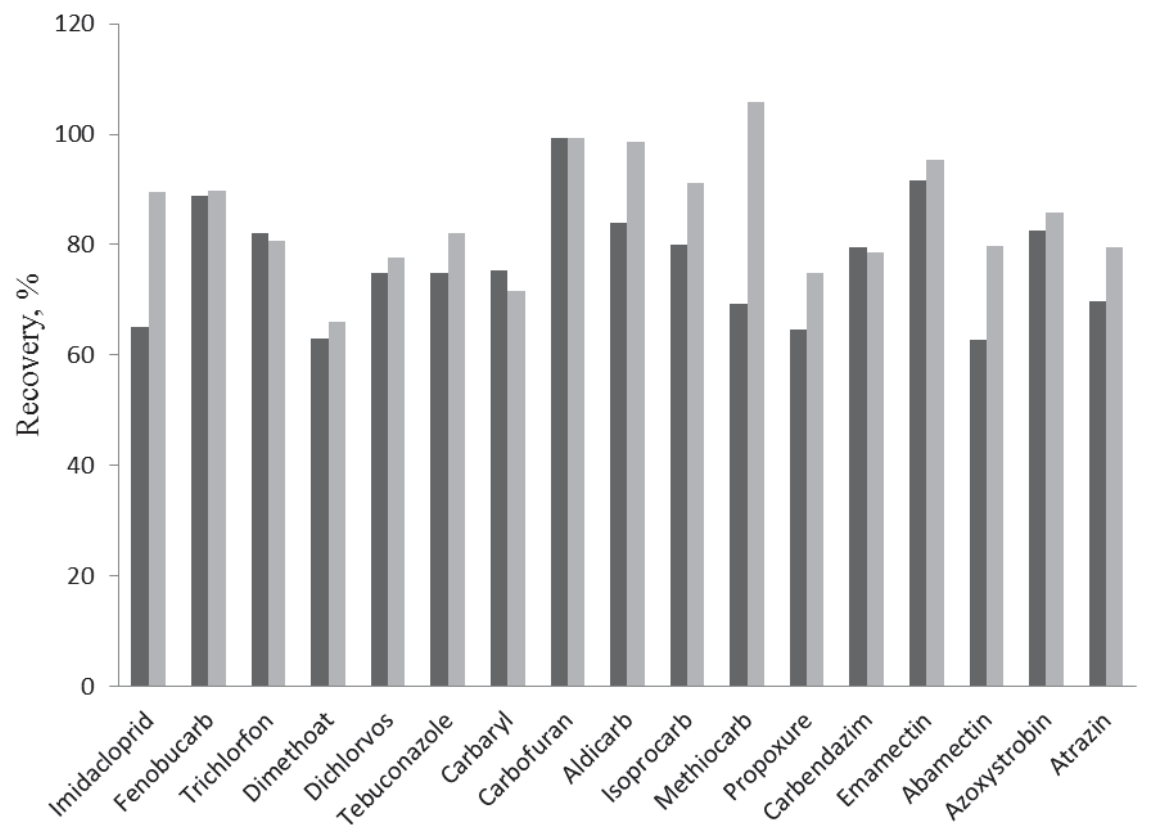

Fig. 3. The recoveries of pesticides obtained from two procedures with using and not using GCB (7.5 mg) in d-SPE step ( $\square$ : d-SPE without using GCB and $\square:$ d-SPE with using GCB) 


\subsection{Matrix effect assessment}

Matrix effect is the effect on an analytical method caused by all other components of the sample beside the specific compound to be quantified. Ion suppression and enhancement are the two causes of the matrix effect. That is why matrix effect is an important criterion in every mass spectrometry method. A matrix effect higher than $20 \%$ must be eliminated or compensated. Matrix effects vary according to the cleanliness of the extracts and the compounds.

The matrix effect is the drawback of QuEChERS method especially for complex matrices. Green teas give a very high matrix effect because of the existence of many pigments. This modified QuEChERS method eliminated most of the pigments and with that it could minimize the matrix effect. Figure 4 shows the matrix effect on the analysed pesticides. Most pesticides gave signals of lower intensities in the matrix than in solvents. However, the matrix effects on all analysed pesticides were within $\pm 20 \%$. To eliminate efficiently the effects of matrix, the matrix-matched calibration technique was used.

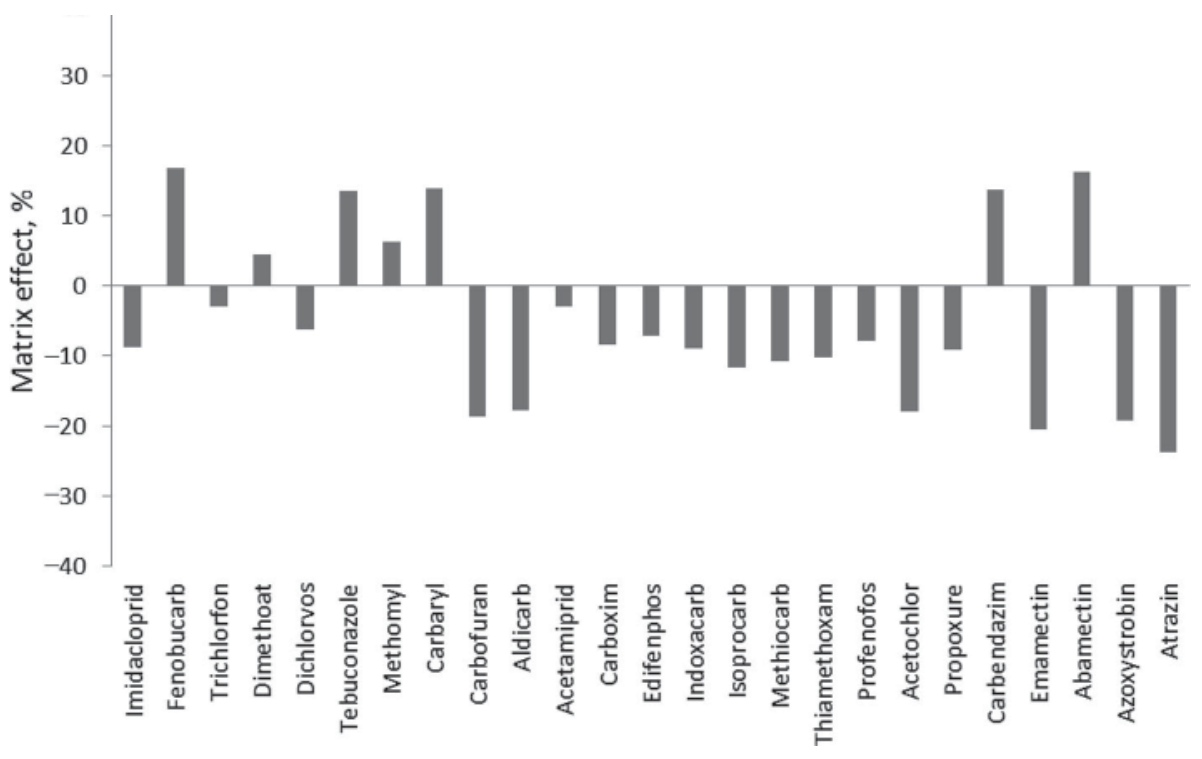

Fig. 4. Green tea matrix effect of pesticides by using modified QuEChERS method

\subsection{Method validation}

For selectivity, every compound had two signals from two product ions (Table 1). Ion ratios of the compounds in the samples were also compared to that in the standards. The relative ion intensities have to meet the criteria given by EU (EUROPEAN COMMISSION, 2002).

The repeatabilities and recoveries obtained with this method are presented in Table 3 . For most pesticides at three levels of concentration, the relative standard deviations (RSD\%) were lower than $20 \%$ (except for profenofos at $100 \mu \mathrm{g} \mathrm{kg}^{-1}$ ) and the recoveries $(\mathrm{R} \%$ ) were between $70-120 \%$. These indicated that this method had accuracy appropriate for the quantification of pesticide multi-residues in green tea. 
Table 3 . The repeatability and recovery at 3 concentration levels $(n=6)$

\begin{tabular}{|c|c|c|c|c|c|c|}
\hline \multirow[t]{2}{*}{ Pesticides } & \multicolumn{2}{|c|}{$10 \mu \mathrm{g} \mathrm{kg}^{-1}$} & \multicolumn{2}{|c|}{$100 \mu \mathrm{g} \mathrm{kg}^{-1}$} & \multicolumn{2}{|c|}{$1000 \mu \mathrm{g} \mathrm{kg}^{-1}$} \\
\hline & RSD\% & $\mathrm{R} \%$ & RSD \% & $\mathrm{R} \%$ & RSD \% & $\mathrm{R} \%$ \\
\hline Acetochlor & 11 & 76.9 & 6.3 & 90.5 & 9.3 & 83.0 \\
\hline Aldicarb & 8.4 & 111 & 9.0 & 118 & 8.1 & 109 \\
\hline Atrazine & 12 & 91.2 & 9.6 & 91.2 & 4.4 & 96.7 \\
\hline Azoxystrobin & 18 & 71.1 & 17 & 78.5 & 15 & 75.3 \\
\hline Abamectin & 16 & 85.4 & 19 & 93.9 & 12 & 92.0 \\
\hline Acetamiprid & 17 & 89.5 & 15 & 94.4 & 11 & 91.4 \\
\hline Carbaryl & 6.2 & 87.8 & 8.8 & 89.3 & 7.6 & 81.9 \\
\hline Carbofuran & 9.4 & 88.9 & 9.1 & 89.4 & 5.9 & 89.1 \\
\hline Carbendazim & 7.6 & 110 & 5.4 & 113 & 5.0 & 111 \\
\hline Carboxin & 7.5 & 82.5 & 7.7 & 87.6 & 8.9 & 86.6 \\
\hline Dichlorvos & 16 & 75.2 & 13 & 73.2 & 9.1 & 82.2 \\
\hline Dimethoat & 5.9 & 82.0 & 9.2 & 75.4 & 4.4 & 77.3 \\
\hline Edifenphos & 9.6 & 74.6 & 7.8 & 82.3 & 7.1 & 83.2 \\
\hline Emamectin & 15 & 98.8 & 8.0 & 96.7 & 18 & 93.9 \\
\hline Fenobucarb & 8.4 & 84.3 & 7.2 & 83.6 & 7.3 & 90.5 \\
\hline Imidacloprid & 11 & 97.8 & 10 & 95.9 & 6.1 & 96.8 \\
\hline Indoxacarb & 16 & 93.3 & 12 & 81.9 & 11 & 88.4 \\
\hline Isoprocarb & 8.2 & 79.4 & 7.4 & 75.8 & 7.0 & 73.4 \\
\hline Methiocarb & 19 & 76.0 & 19 & 78.6 & 13 & 80.3 \\
\hline Methomyl & 19 & 89.9 & 6.3 & 94.5 & 3.1 & 92.0 \\
\hline Profenophos & 17 & 82.6 & 23 & 73.5 & 19 & 71.3 \\
\hline Propoxure & 5.8 & 81.9 & 5.6 & 85.2 & 5.4 & 83.6 \\
\hline Terbuconazole & 10 & 108 & 11 & 108 & 9.9 & 113 \\
\hline Thiamethoxam & 7.5 & 82.5 & 8.7 & 95.5 & 5.2 & 86.2 \\
\hline Trichlorfon & 10 & 91.9 & 6.9 & 83.2 & 4.3 & 81.2 \\
\hline
\end{tabular}

The limit of detection (LOD) and limit of quantification (LOQ) were estimated from the signal to noise $(\mathrm{S} / \mathrm{N})$ ratios of the pesticide peaks. All pesticides could be quantified at the concentration of $10 \mu \mathrm{g} \mathrm{kg}$ - without any concentration steps. This value is acceptable compared to the default maximum residue level $\left(\mathrm{MRL}=10 \mu \mathrm{g} \mathrm{kg}^{-1}\right.$ ).

The linearity was checked in the range of $1-200 \mathrm{ng} \mathrm{ml}^{-1}$. The response of the matrix matched standard was considered linear when the coefficient of determination $\left(\mathrm{r}^{2}\right)$ was equal to or higher than 0.99 . For all analysed pesticides, the linearity range was from $2 \mathrm{ng} \mathrm{ml}^{-1}$ to $200 \mathrm{ng} \mathrm{ml}^{-1}$. A few pesticides even showed lower sensitivity. Because the sample weight was $3 \mathrm{~g}$ and the acetonitrile extract volume was $15 \mathrm{ml}$, the linearity calculated for samples was from $10 \mu \mathrm{g} \mathrm{kg}^{-1}$ to $100 \mu \mathrm{g} \mathrm{kg}^{-1}$. 


\subsection{Analysis of real samples}

Once validated, the proposed method was applied to determine 25 pesticides in 20 different dried green tea samples collected in the Hanoi market.

The results are shown in Table 4. Ten of twenty samples were found to be positive to pesticides from different chemical groups, especially imidacloprid and acetamiprid (neonicotinoid insecticides). Most of the pesticide concentrations were of above $10 \mu \mathrm{g} \mathrm{kg}^{-1}$ (default MRL).

Table 4. Pesticide residues found in dried green tea samples and their concentration

\begin{tabular}{|c|c|c|c|}
\hline Sample ID & Pesticides & Sample conc., $\mu \mathrm{g} \mathrm{kg}^{-1}$ & Class \\
\hline \multirow[t]{2}{*}{ S1 } & Imidacloprid & 10 & Neonicotinoid insecticide \\
\hline & Acetamiprid & 154 & Neonicotinoid insecticide \\
\hline $\mathrm{S} 2$ & Acetamiprid & 5.7 & Neonicotinoid insecticide \\
\hline \multirow[t]{3}{*}{ S9 } & Imidacloprid & 5.6 & Neonicotinoid insecticide \\
\hline & Acetamiprid & 21 & Neonicotinoid insecticide \\
\hline & Carbendazim & 6.4 & Benzimidazole fungicide \\
\hline \multirow[t]{3}{*}{$\mathrm{S} 10$} & Imidacloprid & 42 & Neonicotinoid insecticide \\
\hline & Acetamiprid & 19 & Neonicotinoid insecticide \\
\hline & Thiamethoxam & 150 & Neonicotinoid insecticide \\
\hline \multirow[t]{3}{*}{ S11 } & Imidacloprid & 28 & Neonicotinoid insecticide \\
\hline & Acetamiprid & 45 & Neonicotinoid insecticide \\
\hline & Fenobucarb & 6.7 & Carbamate insecticide \\
\hline \multirow[t]{3}{*}{$\mathrm{S} 12$} & Imidacloprid & 32 & Neonicotinoid insecticide \\
\hline & Acetamiprid & 48 & Neonicotinoid insecticide \\
\hline & Fenobucarb & 17 & Carbamate insecticide \\
\hline $\mathrm{S} 13$ & Emamectin & 64 & Macrycyclic lactone insecticide \\
\hline S16 & Acetamiprid & 16 & Neonicotinoid insecticide \\
\hline \multirow[t]{2}{*}{$\mathrm{S} 18$} & Acetamiprid & 22 & Neonicotinoid insecticide \\
\hline & Carbofuran & 86 & Carbamate insecticide \\
\hline $\mathrm{S} 20$ & Acetamiprid & 19 & Neonicotinoid insecticide \\
\hline
\end{tabular}

\section{Conclusions}

A modified QuEChERS method was proposed for the determination of pesticide multiresidues in dried green tea. The green tea matrix effects were reduced by the addition of lead acetate in the partition step and the use of GCB in the clean-up step. The validation data show that this method has good accuracy and sensitivity and could be applied for the determination of pesticide multi-residue in green tea samples.

Financial supports from the Vietnam Food and Drug Administration are gratefully acknowledged. The authors wish to extend thanks to professor Hue Pham-Gia from Hanoi University of Pharmacy for valuable pieces of advice. 


\section{References}

A.O.A.C. (2010): Official methods of analysis (18th rev. 3), -in: Horwitz, W. \& Latimer, G.W. (Eds) Association of Official Analytical Chemists, Inc., Guithersburg, MD, USA. Official Method 2007.01 Pesticide residues in foods by acetonitrile extraction and partitioning with magnesium sulfate, pp. 17-26.

Anastassiades, M., Lehotay, S.J., Stajnbaher, D. \& Schenck, F.J. (2003): Fast and easy multiresidue method employing acetonitrile extraction/partitioning and dispersive solid-phase extraction for the determination of pesticide residues in produce. J. AOAC Int., 86, 412-431.

BS EN (2008): Foods of plant origin. Determination of pesticide residues using GC-MS and/or LC-MS/MS following acetonitrile extraction/partitioning and clean-up by dispersive SPE. QuEChERS-method. BS EN 15662

Chen, G., CAO, P. \& LiU, R. (2011): A multi-residue method for fast determination of pesticides in tea by ultraperformance liquid chromatography-electrospray tandem mass spectrometry combined with modified QuEChERS sample preparation procedure. Food Chem., 125, 1406-1411.

Cho, S.K., Abdel-Aty, A.M., Choi, J.H., Jeong, Y.M., Shin, H.C., Chang, B.J., Lee, C. \& Shim, J.H. (2008): Effectiveness of pressurized liquid extraction and solvent extraction for the simultaneous quantification of 14 pesticide residues in green tea using GC. J. Sep. Sci., 31, 1750-1760.

Dai, R., Ren, X., He, X. \& Huo, Y. (2011): Convenient analytical method for quantitative determination of 23 pesticide residues in herbs by gas chromatography mass spectrometry. Bull. Environ. Contam. Toxicol., 86, $559-564$.

European Commission (2002): Decision 2002/657/EC of 12 August 2002 implementing Council Directive 96/23/EC concerning the performance of analytical methods and the interpretation of results.

Fan, C.L., Chang, Q.Y., PAng, G.F., Li, Z.Y., Kang, J., PAn, G.Q., Zheng, S.Z., Wang, W.W., Yao, C.C. \& Ji, X.X. (2013): High-throughput analytical techniques for determination of residues of 653 multiclass pesticides and chemical pollutants in tea, Part II: Comparative study of extraction efficiencies of three sample preparation techniques. J. AOAC Int., 96, 432-440.

Graham, H.N. (1992): Green tea composition, consumption, and polyphenol chemistry. Prev. Med., 21, 334-350.

Guan, Y., TAng H., Chen, D., Xu, T. \& Li, L. (2013): Modified QuEChERS method for the analysis of 11 pesticide residues in tea by liquid chromatography-tandem mass spectrometry. Anal. Methods, 5, 3056-3067.

Huang, Z., Li, Y., Chen, B. \& YaO, S. (2007): Simultaneous determination of 102 pesticide residues in Chinese teas by gas chromatography-mass spectrometry. J. Chromatog. B, 853, 154-162.

Lehotay, S.J., Kok, A., Hiemstra, M. \& Bodegraven, P. (2005): Validation of a fast and easy method for the determination of residues from 229 pesticides in fruits and vegetables using gas and liquid chromatography and mass spectrometric detection. J. AOAC Int., 88, 595-614.

Lozano, A., Rajski, L., Belmonte-Valles, N., Ucles, A., Ucles, S., Mezcua, M. \& Fernandez-Alba, A.R. (2012): Pesticide analysis in teas and chamomile by liquid chromatography and gas chromatography tandem mass spectrometry using a modified QuEChERS method: Validation and pilot survey in real samples. J. Chromatog. A., 1268, 109-122.

Nguyen, T.D., Lee, K.J., Lee, M.H. \& Lee, G.H. (2010): A multiresidue method for the determination 234 pesticides in Korean herbs using gas chromatography mass spectrometry. Microchem. J., 95, 43-49.

Rajski, L., Lozano A., Belmonte-Valles, N., Ucles, A., Ucles, S., Mezcua, M. \& Fernandez-Alba, A.R. (2013): Comparison of three multiresidue methods to analyse pesticides in green tea with liquid and gas chromatography/tandem mass spectrometry. Analyst, 138, 921-931.

REDIFF.СOM (2012): Biggest tea producing countries in the world. http://www.rediff.com/business/slide-show/slideshow-1-biggest-tea-producing-countries-in-the-world/20120313.htm.

Shoeibi, S., Amirahmadi, M., Rastegar, H., Khosokhavar, R. \& Khanghah, A.M. (2013): An applicable strategy for improvement recovery in simultaneous analysis of 20 pesticides residue in tea. J. Food Sci., 78, 792-796.

Stahnke, H., Kittlaus, S, Kempe, G. \& Alder, L. (2012): Reduction of matrix effects in liquid chromatography electrospray ionization-mass spectrometry by dilution of the sample extracts: How much dilution is needed? Anal. Chem., 84, 1474-1482.

Steiniger, D., Lu, G., Butler, J., Phillips, E. \& Fintschenko, Y. (2010): Determination of multiresidue pesticides in green tea by using a modified QuEChERS extraction and ion-trap gas chromatography/mass spectrometry. $J$. AOAC Int., 93, 1169-1179.

Wang, S.F., Zhang, S.J., Dong, C.H., Wang, G.Q., Guo, J.F. \& Sun, W.Y. (2013): Simultaneous determination of four herbicide and pesticide residues in Chinese green tea using QuEChERS purification procedure and UPLC-MS/MS analysis. Adv. Mat. Res., 634, 1586-1590. 